\title{
Functional Performance in School Going Cerebral Palsy Children
}

\section{Fahad Asif1', Asifa Javaid², Shoaib Waqas ${ }^{3}$, Hafiz Muhammad Asim ${ }^{4}$}

${ }^{1}$ Student, Lahore, ${ }^{2}$ Lecturer, Lahore ${ }^{3}$ Associate Professor, ${ }^{4}$ Professor

${ }^{1-4}$ Lahore College of Physical therapy, Lahore Medical \&Dental College

Author's Contribution

1, 4 Conception and design, Collection and assembly of data, ${ }^{2-3}$ Analysis and interpretation of the data, ${ }^{1-2}$ Critical revision of the article for important intellectual content, Statistical expertise ${ }^{1}$ Final approval and guarantor of the article.

Article Info.

Received: Jan 8, 2019

Acceptance: June 7, 2021

Conflict of Interest: None

Funding Sources: None

Address of Correspondence

Dr Asifa Javaid

Email ld: Asifajavaid444@gmail.com

Cite this article as: Asif MF, Javaid A,

Waqas S, Asim HM. Functional

Performance in School Going Cerebral Palsy Children. JRCRS. 2021; $\quad 9(1) . \quad 22-. \quad$ DOI: https://dx.doi.org/10.53389/JRCRS.20 $\underline{21090105}$

\section{A B S T R A C T}

Background: A cerebral palsy is a group of non-progressive neurodevelopmental disorder of movement and posture due to lesion and anomalies of the brain that arise early developmental stages. Activity and participation is a complex interaction of life performances of Cerebral Palsy (CP) children and their families with their environment. $\mathrm{CP}$ children have neuro impairment and activity restrictions in educational and social environment. Participating in day to day school activities has shown positive influence on mental and developmental skills, social relationship and health.

Objective: To evaluate the functional performance in school going cerebral palsy children. Methodology: The descriptive case series was conducted on 34 school going spastic cerebral palsy children. The data was collected from Compass Special School and Rising Sun Institution, Lahore of Gross Motor Functional Classification System (GMFCS) level I and II. Ten children were having GMFCS level II and 24 had GMFCS level I. The sampling strategy utilized was non-probability convenience sampling. The duration of the study was from August 2018 to January 2019. The Functional performance was assessed using School Functional Assessment (SFA) questionnaire.

Results: The level of school performance in Cerebral Palsy Children of GMFCS I and II indicated that the majority of children $64.71 \%$ had high performance and $5.88 \% \mathrm{CP}$ children were independent, $26.47 \%$ had moderate performance and $2.94 \%$ had low performance in school activities.

Conclusion: Majority of school going CP children with GMFCS level I \& II have high performance in school tasks.

Key words: Cerebral Palsy, Functional Performance, School Functional Assessment

\section{Introduction}

Cerebral palsy is a group of non-progressive neurodevelopmental disorder of movement and posture due to lesion and anomalies of brain that arise early developmental stages. ${ }^{1}$ Cerebral Palsy is characterized by sensory impairments, learning disabilities, cognitive impairments, problem with manual dexterity, behavioural problems, seizures, speech and language deficits. ${ }^{2}$ In addition, the anxiety and stress levels also increase with growing age which affects their activities. ${ }^{3} \mathrm{CP}$ individual are at a higher risk of fractures throughout their life because of improper developed musculoskeletal system and impaired balance and coordination. ${ }^{4}$ The prevalence of blindness, intellectual disability and hearing loss is higher in children with cerebral palsy as compared to healthy children. ${ }^{5}$ Two or three children per thousand live births develop cerebral palsy. ${ }^{6}$ Evidence on cerebral palsy suggests that $70-80 \%$ cases are due to prenatal factors and there is minor role of birth asphyxia. The antenatal risk factors for cerebral palsy include gender (male), multiple gestations, viral infection and low gestational age. ${ }^{7}$ The CP adults also have higher risk of cardiovascular disorders and other metabolic syndromes due to impaired mobility as compared to the healthy population. ${ }^{8}$ The International Classification of Functioning, Disability, and Health (ICF), separated CP children into three domains of functioning; body structure 
and function (body domain), activities (individual domain) and participation (social domain). CP children are classified on the basis of their types, location of damage, and level of motor impairment (Gross Motor Function Classification System) ${ }^{9}$

Activity and participation is a complex interaction of life performances of CP children and their families with their environment. ${ }^{9}$ Participation is defined by World Health Organization (WHO) as involvement in life situation. ${ }^{10}$ Participation can be assessed by evaluating the life habits i.e. activities of daily routine, difficulties in performing daily routine task and social habits. ${ }^{11}$ Awareness about disabilities of CP children in education system increases the number of enrollments of $C P$ children in regular public schools and they are expected to participate in different activities. ${ }^{9} \mathrm{CP}$ children participate in different activities of school include artistic, creative, physical sport, social, cultural, skilled-based and work activities. There is evidence of positive influence on mental and developmental skills, social relationship and health by participating in day to day formal and informal activities. ${ }^{10}$ Mental health and musculoskeletal pain are considered to be the most common barriers to participation in physical activities for $\mathrm{CP}$ children. ${ }^{12}$ Participation in daily routine activities is also affected by the social, attitudinal and physical environment. ${ }^{13} \mathrm{CP}$ children participate in different activities which are low intensity and involve high enjoyment; their participation in different activities increases opportunities to develop skills and socialization. Lack of functional participation affects long-term health and fitness. ${ }^{14}$ Learning abilities in CP children will be enhanced by participation in activities of daily living. ${ }^{15}$

School Functional assessment (SFA) is
developed to assess school-related functional
performance. ${ }^{9}$ SFA measures the participation of children in the education setting. ${ }^{16}$ SFA is used to measure learning disabilities, functional participation limitation in classrooms and playground in general and special population. ${ }^{17}$ According to ICF, CP children have neuro impairment and activity restrictions in education and social environment. The neuro impairment such as learning disability present in 40\% CP children, epilepsy $35 \%$, visual impairment $20 \%$ and hydrocephalus $9 \%$ affect their participation in school. Additional to this speech, language, perception, behavior and gross and fine motor functions are affected by limited range of motion. ${ }^{18}$ The aim of this study is to evaluate the functional performance of a CP child at school in an educational environment. This will potentially help future therapists and care providers to get to know about the particular limitations of a CP child, and therefore, they can facilitate them in performing better ensuring better achievement of goals with effective education.

\section{Methodology}

A descriptive case series was conducted on 34 school-going spastic cerebral palsy children. The sample was calculated by WHO Sample size calculator using $0.2 \%$ prevalence $(P)$, a margin of error as $2 \%$ and confidence interval as $95 \%$. The study settings were Mobility Rising Sun Institution and Compass Special School Lahore. The sampling strategy utilized was nonprobability convenience sampling. The duration of the study was from August 2018 to January 2019. Data was analyzed using SPSS version 21. CP children aged between $6-12$ years and children who were able to follow commands were included. The baseline characteristics were taken on Gross Motor Functional Classification Scale level I and II. Children with uncontrolled seizures, hearing and visual impairments and $\mathrm{CP}$ children with other Levels of GMFCS were excluded from the study. School Functional Assessment questionnaire was used to assess participation \& cognition/behavioural tasks of school. SFA has three major components to measure the functional status of children in social participation, task support in physical and cognitive/behavioural and activity performance. The reliability of the questionnaire to measure functional activity in school was 0.94. ${ }^{26}$

Data was entered by using Statistical package for social science (SPSS) version 23 and software was used for data analysis. The Study Variable were presented in the form of descriptive statistics (tables, graphs, and percentages).

Permission from the Ethics Committee of LCPT was obtained. Questionnaire was accompanied by an information sheet that explains the nature and purpose of the study and consent was taken. 


\section{Results}

Mean age of the children with $\mathrm{CP}$ was 8.64 years with standard deviation \pm 3.36 . Out of $34 \mathrm{CP}$ children, 29 were boys and 5 were girls; 24 children were at GMFCS level I and 10 were at GMFCS level II.

Out of the total, $64.71 \%$ children at GMFCS level I, showed participation with assistance and $5.88 \%(\mathrm{n}=2)$ showed modified full participation. In the physical task, $70.58 \%(\mathrm{n}=24)$ CP children required minimal assistance and $5.9 \% \quad(n=2)$ required no assistance. In cognitive/behavioral activities, $73.5 \% \quad(n=25)$ required minimal and 2.94\% $(n=1)$ required no assistance. (Figure 1)

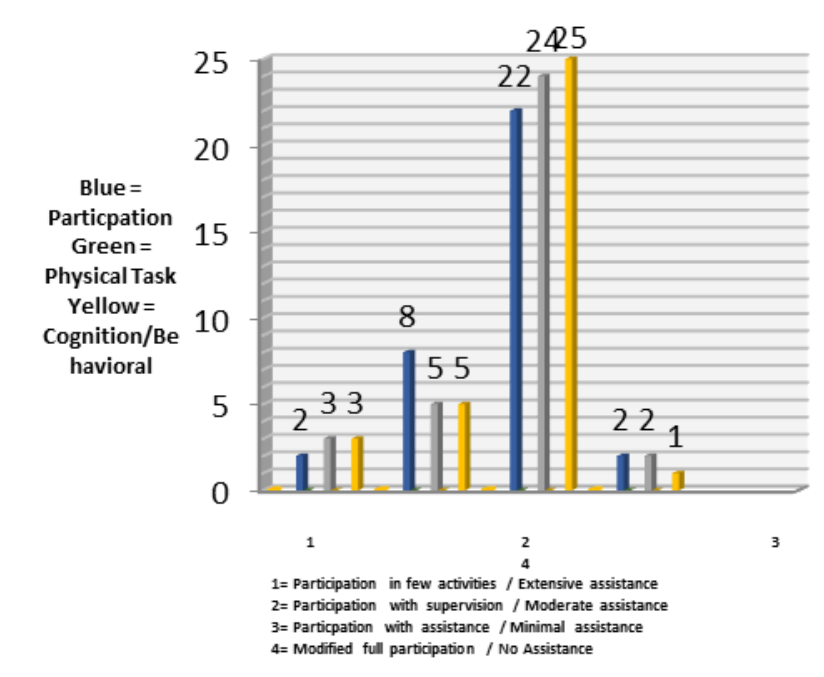

Figure 1: Frequency of Participation, Physical Task \& Cognitive/Behavioral

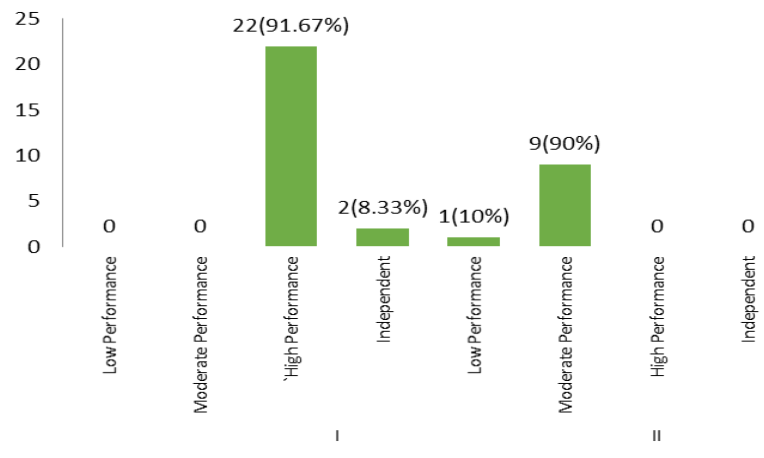

Figure 2: Frequency of Performance at GMFCS Level I and II

There was a difference in the overall performance of Cerebral Palsy GMFCS level I and II. Out of 34 school going CP children, 10 children were at GMFCS Level II out of which 1 was falling in category of low performance and 9 were having moderate performance. 24 children were with GMFCS Level I out of which 22 were having high performance and 2 children were in the category of independent (need no assistance). (Figure 2)

The results showed that, out of all the students with GMFCS Level II, 5.88\% ( $\mathrm{n}=2)$ demonstrated participation in fewer activities and $23.51 \%(n=8)$ showed participation with supervision. Similar results were shown in physical task and cognitive/ behavioral that $8.82 \%$ $(n=3)$ children required extensive assistance, $14.7 \%(n=5)$ $\mathrm{CP}$ Children required moderate assistance in performing physical tasks and $8.83 \%(\mathrm{n}=3) \mathrm{CP}$ Children requires extensive assistance and $14.7 \%(n=5)$ required moderate assistance in performing cognitive/behavioral activities.

$\frac{\text { Discussion }}{\text { In the present study, school functional }}$
performance was evaluated among participants with cerebral palsy by the utilization of a reliable tool for performance assessment known as School Functional Assessment questionnaire (SFA). Most participants were categorized according to Gross Motor Functional Classification System level I and II and their functional activities at school were assessed. The results of current study shows performance differences in both GMFCS levels. These results were similar to the study conducted previously by Schenker, in which he included CP children with different types and different GMFCS levels. In his study, he concluded significant differences in levels of participation and levels of activity performance between different types of CP and GMFCS levels. According to him children at GMFCS level II performed significantly better than children at level III. Our study also suggests that activity performance increases as motor function level increases. ${ }^{9}$

Despite the absence of comparison group, this study contribute to the understanding of association between GMFCS levels and high performance. Minimal assistance was needed by participants of level I and II. Marry Law conducted a study in which he included $\mathrm{CP}$ children under the category of children with physical disabilities and concluded that these children required 
minimal assistance during outside or formal activities. ${ }^{10}$ The independency of performing and participating in activities is not only linked with lower level of GMFCS but also correlated to nu merous other factors. However previous literature has emphasized the fact that little assistance is required in walking or standing by participants at lower level i.e Level II as compared to Level III. ${ }^{19}$ Motor function capabilities are directly related to active physical participation. Most of the previous studies have noted that severity of motor dysfunction is associated with disruption in participation in recreation and other daily life activities however, our study specifies particular school related activities which are of equally prime importance. ${ }^{20}$ GMFCS level I participants showed better performance and had minimum difficulty in performing activities of daily living i.e hygiene, eating and drinking. ${ }^{21}$ According to the Virginia Wong study, Most CP children with GMFCS level I could be able to achieve the functional independence in their activities which explains our results that children with GMFCS level I have high performance or independent to perform most of their tasks. ${ }^{25}$

The striking feature of present study is utilization of reliable instrument for measurement of school functional performance. Previous studies have largely focused on assessment of activities of daily living, social skills, cognitive functions individually ignoring the importance of functional performance at school. Thus, the study provides the framework for care takers and rehabilitators to focus on improving their functional performance, so enabling them to perform better at school. Also participation of children in all setups i.e classroom, playground, toilet, computer laboratories were assessed which was completely neglected in previous studies. Additionally, both genders were enrolled for the study providing heterogeneous distribution. The major weak point of the study is that it did not include all levels of GMFCS. However, this inadequate inclusion of other levels did not interfere with main objective of the study. Further assessment would warrant such evaluation.

\section{Conclusion}

The study concluded that majority of the school going children with cerebral palsy had high functional performance. Most of the children with GMFCS level I required minimal assistance in performing their physical and cognitive/behavioral tasks as compared to level II.

Recommendations: Future recommendations include that study can be improved by increasing the sample size and by choosing further GMFCS levels to assess functional status in school.

Discloser: This article is retrieved from thesis held in 2019 at Lahore College of Physical therapy, LM\&DC

\section{References}

1. Lemmens RJ, Janssen-Potten YJ, Timmermans AA, Defesche A, Smeets RJ, Seelen HA. Arm hand skilled performance in cerebral palsy: activity preferences and their movement components. BMC neurology. 2014;14(1):52.

2. Kennes J, Rosenbaum P, Hanna SE, Walter S, Russell D, Raina $P$, et al. Health status of school-aged children with cerebral palsy: information from a population-based sample. Developmental medicine and child neurology. 2002;44(4):240-7.

3. Whitney DG, Peterson MD, Warschausky SA. Mental health disorders, participation, and bullying in children with cerebral palsy. Developmental Medicine \& Child Neurology. 2019. ;61(8):937-42

4. Whitney DG, Alford Al, Devlin MJ, Caird MS, Hurvitz EA, Peterson MD. Adults With Cerebral Palsy Have Higher Prevalence of Fracture Compared With Adults Without Cerebral Palsy Independent of Osteoporosis and Cardiometabolic Diseases. Journal of Bone and Mineral Research. 2019. 34(7):1240-7.

5. McGuire DO, Tian LH, Yeargin-Allsopp M, Dowling NF, Christensen DL. Prevalence of cerebral palsy, intellectual disability, hearing loss, and blindness, National Health Interview Survey, 2009-2016. Disability and health journal. 2019;12(3):443-51.

6. Löwing K, Arredondo YC, Tedroff M, Tedroff K. Introduction of the gross motor function classification system in Venezuela-a model for knowledge dissemination. BMC pediatrics. 2015;15(1):111.

7. Arnould C, Penta M, Thonnard J-L. Hand impairments and their relationship with manual ability in children with cerebral palsy. Journal of Rehabilitation Medicine. 2008;39(9):708-14.

8. Heyn PC, Tagawa A, Pan Z, Thomas S, Carollo JJ. Prevalence of metabolic syndrome and cardiovascular disease risk factors in adults with cerebral palsy. Developmental Medicine \& Child Neurology. 2019;61(4):477-83.

9. Schenker R, Coster WJ, Parush S. Neuroimpairments, activity performance, and participation in children with cerebral palsy mainstreamed in elementary schools. Developmental medicine and child neurology. 2005;47(12):808-14. 
10. Law M, King G, King S, Kertoy M, Hurley P, Rosenbaum $P$, et al. Patterns of participation in recreational and leisure activities among children with complex physical disabilities. Developmental medicine and child neurology. 2006;48(5):337-42.

11. Fougeyrollas $P$, Noreau L. Long-term consequences of spinal cord injury on social participation: the occurrence of handicap situations. Disability and Rehabilitation. 2000;22(4):170-80.

12. Ramstad $\mathrm{K}$, Jahnsen $\mathrm{R}$, Skjeldal $\mathrm{OH}$, Diseth $\mathrm{TH}$. Parent-reported participation in children with cerebral palsy: the contribution of recurrent musculoskeletal pain and child mental health problems. Developmental Medicine \& Child Neurology. 2012;54(9):829-35.

13. Fauconnier J, Dickinson HO, Beckung E, Marcelli $M$, McManus V, Michelsen SI, et al. Participation in life situations of 8-12 year old children with cerebral palsy: cross sectional European study. Bmj. 2009;338:b1458.

14. Imms C, Reilly S, Carlin J, Dodd KJ. Diversity of participation in children with cerebral palsy. 2008. 50(5):363-9

15. Pratt B, Baker KW, Gaebler-Spira DJ. Participation of the child with cerebral palsy in the home, school, and community: A review of the literature. Journal of pediatric rehabilitation medicine. 2008;1(2):101-11.

16. Sakzewski L, Boyd R, Ziviani J. Clinimetric properties of participation measures for 5-to 13-year-old children with cerebral palsy: a systematic review. Developmental Medicine \& Child Neurology. 2007;49(3):232-40.

17. Hwang J-L, Davies PL, Taylor MP, Gavin WJ. Validation of School Function Assessment with elementary school children. OTJR: Occupation, Participation and Health. 2002;22(2):48-58.

18. Beckung $E$, Hagberg G. Neuroimpairments, activity limitations, and participation restrictions in children with cerebral palsy. Developmental Medicine \& Child Neurology. 2002;44(5):309-16.

19. Russell DJ, Gorter J. Assessing functional differences in gross motor skills in children with cerebral palsy who use an ambulatory aid or orthoses: can the GMFM-88 help? Developmental medicine and child neurology. 2005;47(7):462-7.

20. Majnemer A, Shevell M, Law M, Birnbaum R, Chilingaryan $G$, Rosenbaum $P$, et al. Participation and enjoyment of leisure activities in school-aged children with cerebral palsy. Developmental Medicine \& Child Neurology. 2008;50(10):751-8.

21. Huang $\mathrm{CY}$, Tseng MH, Chen KL, Shieh JY, Lu L. Determinants of school activity performance in children with cerebral palsy: A multidimensional approach using the ICF-CY as a framework. Research in developmental disabilities. 2013;34(11):4025-33.

22. Wong V, Chung B, Hui S, Fong A, Lau C, Law B, et al. Cerebral palsy: correlation of risk factors and functional performance using the Functional Independence Measure for Children (WeeFIM). Journal of child neurology. 2004;19(11):887-93.

23. Li X.-L., Dong V. AQ., \& Fong, KN. Reliability and validity of school function assessment for children with cerebral palsy in Guangzhou, China. Hong Kong journal of occupational therapy.2015; 26(1), 43-50. 